\title{
Polygenic Resistance of Pepper to Potyviruses Consists of a Combination of Isolate-Specific and Broad-Spectrum Quantitative Trait Loci
}

\author{
Carole Caranta, Véronique Lefebvre, and Alain Palloix \\ INRA, Station d'Amélioration des Plantes Maraîchères, domaine Saint Maurice, BP94, 84143 Montfavet \\ Cedex, France \\ Received 31 March 1997. Accepted 25 June 1997.
}

\begin{abstract}
At least six potyviruses infect pepper crops around the world. Only monogenic resistance with isolate-specific effects or broad-spectrum effects against potyviruses has been identified. Quantitative trait loci (QTLs) for resistance to two potato virus Y (PVY) isolates and to potyvirus $E$ have been mapped in a doubled-haploid progeny from the hybrid between the line Perennial with resistance factors against several potyviruses and the line Yolo Wonder, with 172 DNA markers. Eleven chromosomal regions were found to be associated with quantitative resistance to PVY and potyvirus $E$ by both analysis of variance and nonparametric tests. This resistance results from the association of a major-effect QTL and several minor-effect QTLs. Two minor-effect QTLs originated from the susceptible parent. In addition to additive-effect QTLs, interactions between QTLs were also identified. Based on their spectrum of action, we discriminated QTLs with PVY isolateor potyvirus-specific effect and loci involved in the resistance to several distinct potyviruses. The locations of QTLs were compared with loci having known qualitative effects against potyviruses; QTLs for PVY and potyvirus $E$ resistance were detected in the vicinity of the $p v r 2$ and pvr6 loci. The origin of the broad-spectrum resistance against potyviruses and the relationships between major genes and QTLs are discussed.
\end{abstract}

Additional keywords: Capsicum annuum L., multipotyvirus quantitative resistance, RAPD markers, RFLP.

The genus Potyvirus is the largest of all known plant virus genera. It contains over 180 distinct viruses and most of them cause significant losses in many agriculturally important crop species (Ward and Shukla 1991), including Solanaceous crops (tomato, pepper, potato, and tobacco).

Numerous studies on the genetics of potyvirus resistance are available. Such resistance is usually simply inherited (Provvidenti and Hampton 1992). One feature seems peculiar to genes controlling potyvirus resistance: in species infected by more than one potyvirus (including pepper, maize, Cucurbita moschata, pea, bean, barley, Cucumis sativus, and tomato), loci have often been identified that are involved in phenotypically similar resistance responses to several potyvi-

Corresponding author: Carole Caranta; E-mail: caranta@avignon.inra.fr ruses (Cook and Anderson 1959; McMullen and Louie 1991; Gilbert-Albertini et al. 1993; Provvidenti and Hampton 1993; Fisher and Kyle 1994, 1996; Bauer and Graner 1995; Wai and Grumet 1995; Dogimont et al. 1996; Légnani et al. 1996).

Pepper (Capsicum annuum L.) may be affected by five major potyviruses: potato virus Y (PVY), tobacco etch virus (TEV), pepper mottle virus, pepper veinal mottle virus, and chili veinal mottle virus (Green and Kim 1991). PVY is frequently identified worldwide as a component of viral complexes. PVY isolates have been grouped into three pathotypes $(-0,-1$, and $-1,2)$ with respect to their differential interactions with the $p v r 2^{1}$ and the $p v r 2^{2}$ alleles at the $p v r 2$ locus (GebreSelassie et al. 1985). Gebre-Selassie et al. (1983) isolated a distinct potyvirus, designated potyvirus E, from Portulacca oleracea, that infects pepper under experimental conditions. It differs from the other by its biological (symptoms and hosts range) and antigenic properties. Moreover, we were unable to amplify the potyvirus E capsid with primers universal for PVY isolates (Blanco-Urgoiti et al. 1997), indicating that potyvirus $\mathrm{E}$ is distinct from PVY (C. Caranta, A. Romero, and F. Ponz, unpublished results).

Several major resistance genes showing phenotypically distinct types of responses to potyviruses have been identified in pepper (Palloix 1992). Among them, two are particularly interesting because of their broad spectrum of action. The $p v r 2^{2}$ allele (from $C$. annuum line Florida VR2; Gebre-Selassie et al. 1985; Palloix and Kyle 1995) confers a complete resistance to PVY pathotypes 0 and 1 and also to common isolates of TEV (TEV-C). Moreover, the complementation between $p v r 2^{2}$ and another recessive gene ( $p v r 6$ from the $C$. annuum line Perennial) confers a complete resistance to another potyvirus, the pepper veinal mottle virus (Caranta et al. 1996). The dominant gene Pvr4 was shown to control a complete resistance against all PVY isolates and also to pepper mottle virus (Dogimont et al. 1996).

In a previous study (Caranta and Palloix 1996), we found an absolute resistance to PVY isolate To72, chili veinal mottle virus, and potyvirus E, and a partial resistance to PVY isolate Son41 in the Indian pepper line Perennial. Resistance against PVY isolates and potyvirus $\mathrm{E}$ was assessed in a doubledhaploid (DH) progeny obtained from the $F_{1}$ hybrid between the line Perennial and Yolo Wonder, a potyvirus susceptible line, with a combination of both the intensity of symptoms and the incubation period (named AUSPC [area under the 
symptoms progress curve] resistance index; Caranta and Palloix 1996). Unlike the other potyvirus resistance, line Perennial resistance was shown to be quantitatively expressed and controlled by several genetic factors with an overall recessive mode of inheritance. Correlation studies showed that both isolate-specific and broad-spectrum resistance factors control this polygenic resistance. In this paper we report the molecular mapping of potyvirus resistance factors from the line Perennial and an analysis of the genetic basis of multipotyvirus quantitative resistance, which allows us to make comparisons with the location of major genes and quantitative trait loci (QTLs) involved in virus resistance.

\section{RESULTS}

Status of the pepper intraspecific linkage map.

Ninety-four DH lines obtained from the $\mathrm{F}_{1}$ between the lines Perennial and Yolo Wonder were analyzed with 176

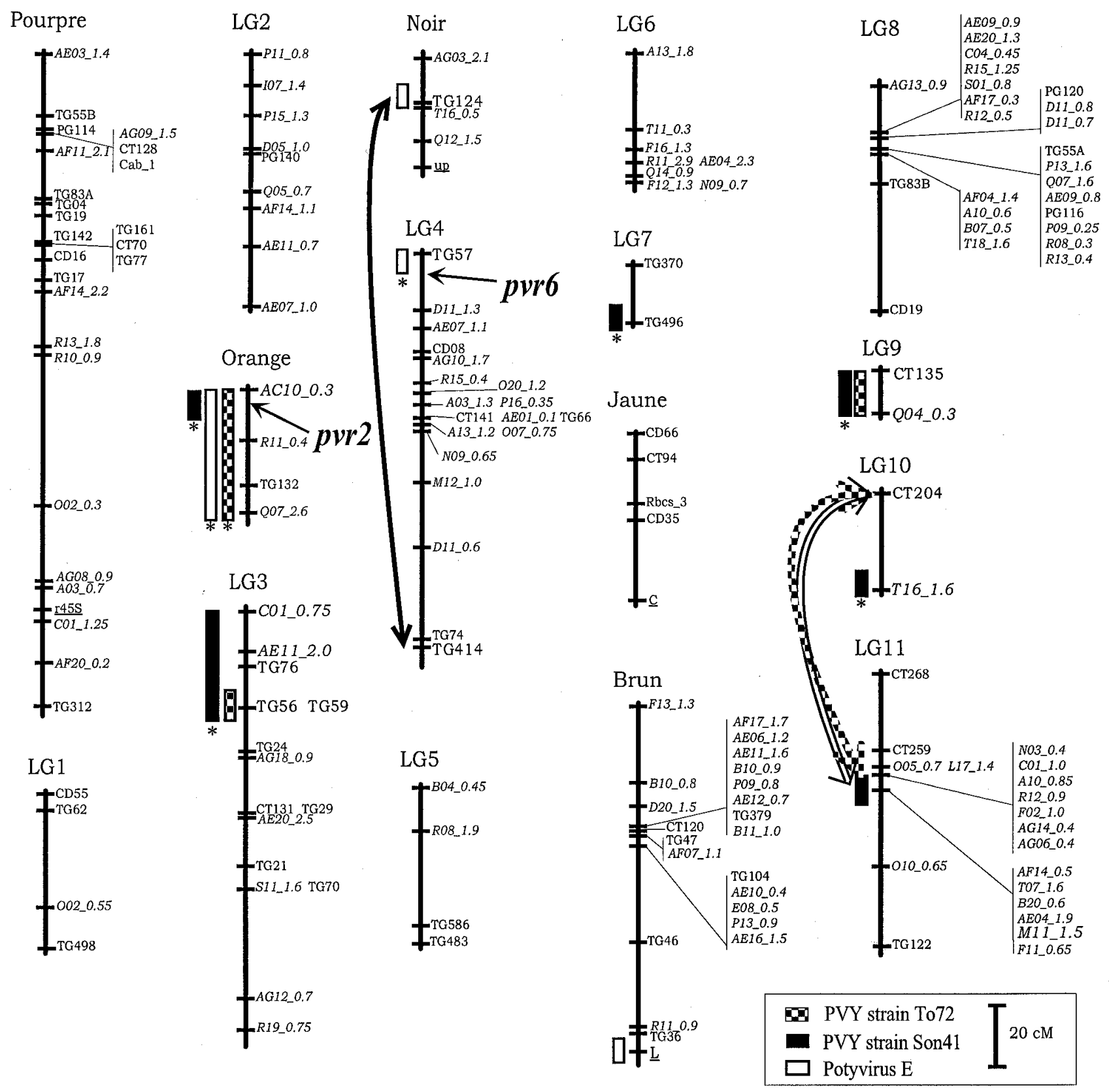

Fig. 1. Linkage map of pepper with the location of quantitaive trait loci (QTLs) involved in potato virus Y (PVY) and potyvirus E resistance. Vertical lines indicate linkage groups (LGs). French color names indicate LGs assigned to chromosomes via mapping of the $L$ (tobacco mosaic virus resistance), $C$ (presence/absence of capsaicin), up (upright position of the fruit), pvr2 (PVY and tobacco etch virus [TEV] resistance), and R45S loci (Pochard 1977). Designations on right of linkage groups represent marker names (random amplified polymorphism DNA loci are italicized; known genes used for assignment to chromosomes are underlined; restriction fragment length polymorphism loci are in normal text). Rectangles represent genomic regions (markers) with additive effect associated with resistance; arrows indicate epistatic effects between loci; stars under rectangles indicate QTLs detected by single-factor analysis of variance. Locations of major genes involved in potyvirus resistance ( $p v r 2$ and $p v r 6$ ) are also indicated. 
markers, of which 172 (110 random amplified polymorphism DNA [RAPD]; 59 restriction fragment length polymorphism [RFLP], and 3 phenotypic markers) were mapped into 16 linkage groups (LGs), spanning a map distance of $1,179 \mathrm{cM}$ (estimated with the Kosambi mapping function) (Fig. 1). This map was estimated to cover about $83 \%$ of the pepper genome, according to previous estimates of genome length (Lefebvre et al. 1995).

Compared with previous intraspecific pepper maps (Lefebvre et al. 1995; Caranta et al. 1997), a new LG was assigned to the chromosome named Orange by Pochard (1977) due to the mapping of the locus $p v r 2$ involved in complete resistance to PVY(0) (allele $p v r 2^{1}$ ), PVY(1), and TEV (allele $p v r 2^{2}$ ). The $p v r 2$ locus was mapped between the RAPD markers AC10_0.3 and R11_0.4 (3.5 cM away from AC10_0.3) on the DH progeny obtained from the cross between the $C$. annuum lines H3 and Vania. Neither the line Perennial nor the line Yolo Wonder possess the alleles for complete resistance (i.e., $p v r 2^{1}$ and $p v r 2^{2}$ ) but it was possible to infer the location of the $p v r 2$ locus via comparative mapping. The markers AC10_0.3, R11_0.4, and TG132 were common to both maps (Fig. 2).

\section{Markers associated with PVY and potyvirus E resistance.}

The association of marker genotypes with potyvirus resistance was assessed by analysis of variance (ANOVA) (Table 1). Since ANOVA did not permit the precise location of the QTL, nor the distinction between one or several QTLs in a genomic region, we assumed that a single QTL was identified when several linked markers were significantly associated with the trait. We localized the QTL close to the marker that displayed the highest $R^{2}$ value. QTLs were also detected by nonparametric tests, which allowed us to confirm the results found with ANOVA. Eleven genomic regions were identified as involved in potyvirus resistance (Fig. 1).

A major-effect QTL associated with both PVY isolates and potyvirus E resistance was detected on chromosome Orange by one-factor ANOVA. Along this linkage group, the marker AC10_0.3 accounted for the highest variation level: $59 \%$ for PVY-To 72, 62\% for potyvirus E, and 25\% for PVY-Son41. As expected, the resistant parent contributed the favorable allele. In order to obtain an estimate of the map position of the QTL, interval mapping was performed for chromosome Orange (Fig. 2). For each resistance, the LOD (logarithm of the odds ratio) score value reached a maximum between the markers AC10_0.3 and R11_0.4, approximately 3 to $4 \mathrm{cM}$ from AC10_0.3.

Additional lower-effect QTLs $\left(R^{2}\right.$ values ranging from 5 to $12 \%$ ) were detected by one-factor ANOVA and two-factor ANOVA with AC10_0.3 as first component (most of them are detected by the one-factor ANOVA model; Table 1). The markers TG56 and TG59 (LG3) and CT135 and Q04_0.3 (LG9) were involved in resistance to both PVY isolates. For the QTL on LG3, the allele from the line Perennial increased the resistance, whereas for the QTL on LG9 the allele from the line Yolo Wonder was more favorable. The other minoreffect QTLs were involved only in resistance to a single PVY isolate or a single potyvirus (PVY or potyvirus E): the markers TG496 (LG7), T16_1.6 (LG10), and M11_1.5 (LG11) in PVY-Son41 resistance and the markers TG124 (chromosome Noir), TG57 (LG4), and $L$ (chromosome Brun) in potyvirus E resistance. The favorable alleles were again present in the resistant parent except for the locus on LG11.

Finally, two digenic epistases were found to have a significant effect on potyvirus resistance. The first one occurred between TG124 (chromosome Noir) and TG414 (LG4) and accounted for $22 \%$ of the measured resistance to PVY-Son41. The second occurred between CT204 (LG10) and M11_1.5 (LG11) and explained $20 \%$ of the resistance to PVY-To72 and $25 \%$ of the resistance to potyvirus E. The most resistant combinations involved one allele from the line Perennial and one allele from the line Yolo Wonder. Moreover, in each case, one of the interacting QTLs alone had an effect on potyvirus resistance.

Multi-factor ANOVA models were written to determine the global $R^{2}$ for each resistance, corresponding to the total part of variance explained by the set of different QTLs. Depending on the resistance considered, the global $R^{2}$ ranged from 66 to 76\%: $71 \%$ for PVY-To72, $66 \%$ for PVY-Son 41 , and $76 \%$ for potyvirus E.

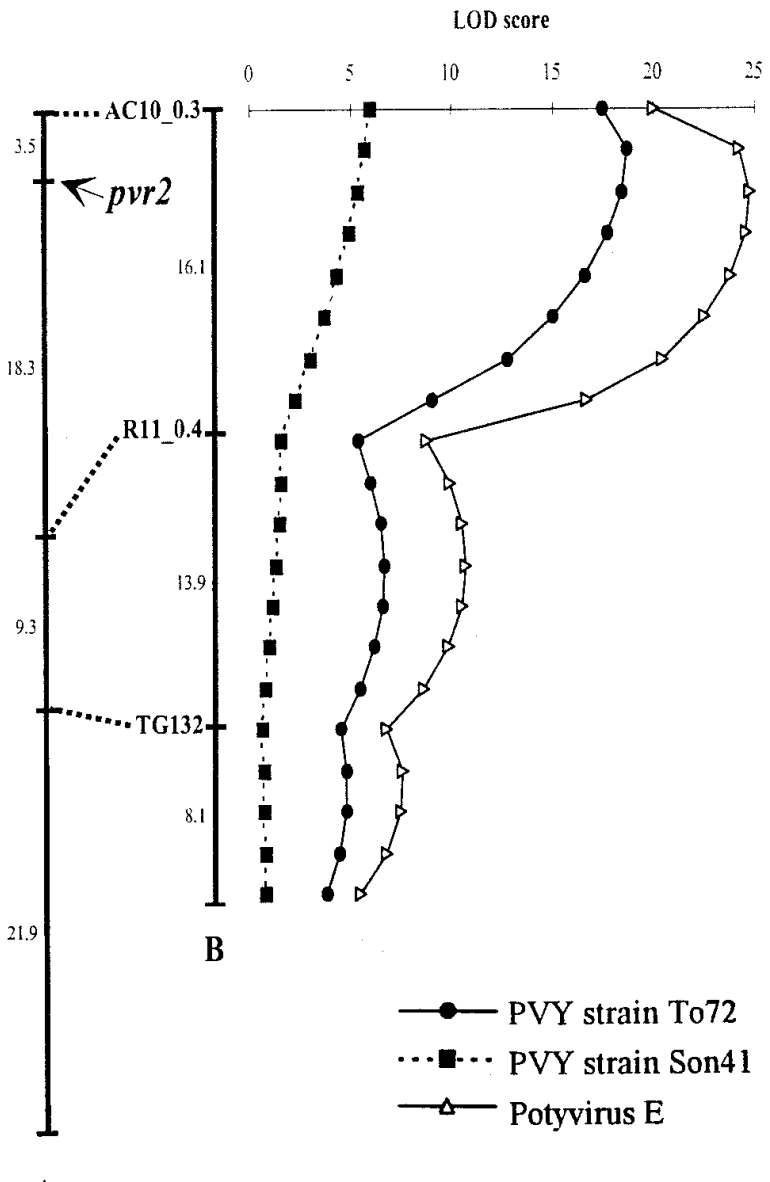

A

Fig. 2. Comparative map of chromosome Orange from Capsicum annuum intraspecific crosses between the lines $\mathrm{H} 3$ and Vania (A) and the lines Perennial and Yolo Wonder (B). Numbers on left of the linkage groups correspond to map distances between markers in cM. LOD score values (obtained with MapmakerQTL; Lander and Botstein 1989) showing associations with resistance to potato virus $\mathrm{Y}$ and potyvirus $\mathrm{E}$ in the doubled-haploid progeny obtained from the $F_{1}$ hybrid between Perennial and Yolo Wonder are indicated. 


\section{DISCUSSION}

\section{Characteristics of putative QTLs for potyvirus resistance.}

Markers significantly associated with PVY and potyvirus E resistance were located in 11 chromosomal regions. The number of resistance factors detected depended on the potyvirus considered: 5 were involved in complete resistance to PVYTo72, 8 in partial resistance to PVY-Son41, and 6 in complete resistance to potyvirus $\mathrm{E}$. The convergent results obtained with the different methods of QTL detection (ANOVA and nonparametric tests) and the significance level used strengthen the involvement in resistance of the detected genomic regions. The total phenotypic variation accounted for by QTLs ranged from 66 to $76 \%$, depending on the resistance. Narrow sense heritability of the traits was estimated to vary from 0.90 to 0.96 (Caranta and Palloix 1996). Thus, the unexplained part of the genetic variation may result from the incomplete coverage of the linkage map and/or from the moderate size of our sample (94 lines), which did not allow us to detect very low effect QTLs.

PVY and potyvirus E resistance arose from the association of a major-effect QTL and several minor-effect QTLs. The detection of minor-effect QTLs (at significance levels ranging from $4.3 \cdot 10^{-3}$ to $9.7 \cdot 10^{-6}$ ) and the total part of the variance explained by the set of QTLs, compared with the variance explained by the major-effect QTL on the chromosome Orange, clearly showed that several genetic factors are involved in resistance expression. Involvement of major-effect QTLs in quantitative resistance to disease has also been found by other authors and led to the expectation that the resistance could be mapped as a qualitative character (for review see Young 1996). Among minor-additive-effect QTLs, two originated from the susceptible parent, Yolo Wonder. QTLs with additive effect control a large part of the resistance to PVY and potyvirus E but we also identified interactions between QTLs (by both ANOVA and nonparametric tests). However, and despite the fact that the $P$ values associated with these resistance QTLs were high, the small size of the population (94 DH lines) and consequently the small number of DH lines in each genotypic class (from 15 to 26 , depending on the resistance considered) did not allow us to reliably identify digenic interactions; these have to be more precisely evaluated on a larger progeny. Interestingly, all the detected interactions involved one allele from the line Perennial and one allele from the line Yolo Wonder. This underlines the influence of the susceptible genetic background in the expression of the resistance; resistance factors from the susceptible parent are not able to control completely the virus infection, but can be directly involved in the resistance or interact with alleles from the resistant parent. These results confirm the polygenic nature of Perennial resistance against PVY and potyvirus E (Caranta and Palloix 1996). They provide original illustration that complete as well as quantitative resistance can result from the association of loci with partial effect.

\section{Genomic regions involved in broad-spectrum and isolate-specific potyvirus resistance.}

If we consider only resistance factors involved in PVY resistance, different types of QTLs were discriminated based on isolate specificity: QTLs specific to one or the other PVY

Table 1. Biometrical parameters for regions of the pepper genome associated with resistance to PVY isolate To72, PVY isolate Son 41 and potyvirus E in the doubled-haploid progeny obtained from the $\mathrm{F}_{1}$ of the cross between the Capsicum annuum lines Perennial and Yolo Wonder

\begin{tabular}{|c|c|c|c|c|c|c|c|c|c|c|}
\hline \multirow[b]{2}{*}{ Location } & \multirow[b]{2}{*}{ Markers } & \multicolumn{3}{|c|}{$\operatorname{PVY}(0)=$ To72 isolate } & \multicolumn{3}{|c|}{$\operatorname{PVY}(1,2)=$ Son 41 isolate } & \multicolumn{3}{|c|}{ Potyvirus E } \\
\hline & & Probability & $R^{2}$ a & Allele $^{b}$ & Probability & $R^{2}$ a & Allele $^{\text {b }}$ & Probability & $R^{2}$ a & Allele $^{b}$ \\
\hline \multicolumn{11}{|c|}{ QTLs with additive effect ${ }^{c}$} \\
\hline \multirow[t]{4}{*}{ Orange } & AC10_0.3 & $<10^{-7}$ & 0.59 & $\mathrm{P}$ & $0.2 \cdot 10^{-6}$ & 0.25 & $\mathrm{P}$ & $<10^{-7}$ & 0.62 & $\mathrm{P}$ \\
\hline & TG132 & $3.7 \cdot 10^{-6}$ & 0.23 & $\mathrm{P}$ & $\ldots$ & $\ldots$ & $\ldots$ & $<10^{-7}$ & 0.31 & $\mathrm{P}$ \\
\hline & R11_0.4 & $9.5 \cdot 10^{-6}$ & 0.22 & $\mathrm{P}$ & $\ldots$ & $\ldots$ & $\ldots$ & $<10^{-7}$ & 0.33 & $\mathrm{P}$ \\
\hline & Q07_2.6 & $2.9 \cdot 10^{-5}$ & 0.18 & $\mathrm{P}$ & $\ldots$ & $\ldots$ & $\ldots$ & $0.5 \cdot 10^{-6}$ & 0.24 & $\mathrm{P}$ \\
\hline LG3 & TG5 $\overline{6}^{\mathrm{d}}$ & $\ldots$ & $\ldots$ & $\ldots$ & $1.6 \cdot 10^{-3}$ & 0.10 & $\mathrm{P}$ & 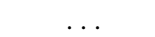 & $\ldots$ & $\ldots$ \\
\hline LG4 & TG57 & $\ldots$ & $\ldots$ & $\ldots$ & $\ldots$ & $\ldots$ & $\ldots$ & $1.9 \cdot 10^{-3}$ & 0.10 & $\mathrm{P}$ \\
\hline LG7 & TG496 & $\ldots$ & $\ldots$ & $\ldots$ & $0.5 \cdot 10^{-3}$ & 0.10 & $\mathrm{P}$ & $\ldots$ & $\ldots$ & $\ldots$ \\
\hline LG9 & CT135 & $\ldots$ & $\ldots$ & $\ldots$ & $1.8 \cdot 10^{-3}$ & 0.12 & YW & $\ldots$ & $\ldots$ & $\ldots$ \\
\hline LG10 & T16_1.6 & $\cdots$ & $\ldots$ & $\ldots$ & $4.3 \cdot 10^{-3}$ & 0.10 & $\mathrm{P}$ & $\cdots$ & $\cdots$ & $\cdots$ \\
\hline \multicolumn{11}{|c|}{ QTLs with additive effect ${ }^{\mathrm{e}}$} \\
\hline \multirow[t]{4}{*}{ LG3 } & TG56 $^{\mathrm{d}}$ & $1.9 \cdot 10^{-3}$ & 0.64 & $\mathrm{P}$ & & . & $\ldots$ & $\ldots$ & $\ldots$ & $\ldots$ \\
\hline & TG76 & $\ldots$ & $\ldots$ & $\ldots$ & $1.1 \cdot 10^{-3}$ & 0.33 & $\mathrm{P}$ & $\ldots$ & $\ldots$ & $\ldots$ \\
\hline & AE11_2.0 & $\ldots$ & $\ldots$ & $\ldots$ & $3.9 \cdot 10^{-3}$ & 0.32 & $\mathrm{P}$ & $\ldots$ & $\ldots$ & $\ldots$ \\
\hline & C01_0.75 & & & $\ldots$ & $2.8 \cdot 10^{-3}$ & 0.32 & $\mathrm{P}$ & $\ldots$ & $\ldots$ & $\ldots$ \\
\hline \multirow[t]{2}{*}{ LG9 } & Q04_1.3 & $9.7 \cdot 10^{-6}$ & 0.67 & YW & $3.6 \cdot 10^{-5}$ & 0.39 & YW & $\ldots$ & $\ldots$ & $\ldots$ \\
\hline & CT13̄5 & $2.1 \cdot 10^{-3}$ & 0.61 & YW & $\ldots$ & $\ldots$ & $\ldots$ & $\ldots$ & $\ldots$ & $\ldots$ \\
\hline Noir & TG124 & $\ldots$ & $\ldots$ & $\ldots$ & $\ldots$ & $\ldots$ & $\ldots$ & $4.0 \cdot 10^{-3}$ & 0.67 & $\mathrm{P}$ \\
\hline Brun & $\mathrm{L}$ & $\ldots$ & $\ldots$ & $\ldots$ & $\ldots$ & $\ldots$ & $\ldots$ & $6.0 \cdot 10^{-4}$ & 0.68 & $\mathrm{P}$ \\
\hline LG11 & M11_1.5 & $\cdots$ & $\ldots$ & $\cdots$ & $2.6 \cdot 10^{-3}$ & 0.33 & YW & $\ldots$ & $\ldots$ & $\ldots$ \\
\hline \multicolumn{11}{|c|}{ QTLs with epistatic effect ${ }^{\mathrm{f}}$} \\
\hline LG10-11 & CT204-M11 & $1.5 \cdot 10^{-5}$ & 0.25 & YW-P & & & $\ldots$ & $5.0 \cdot 10^{-5}$ & 0.20 & YW-P \\
\hline Noir-LG4 & TG414-TG124 & $\ldots$ & $\ldots$ & $\ldots$ & $2.7 \cdot 10^{-5}$ & 0.22 & P-YW & $\ldots$ & $\ldots$ & $\ldots$ \\
\hline
\end{tabular}

a Coefficient of determination.

${ }^{b} \mathrm{P}$ and $\mathrm{YW}$ indicate that the Perennial or the Yolo Wonder allele increase the resistance.

c Single-factor analysis of variance (ANOVA), $\mathrm{P}<0.005$.

${ }^{\mathrm{d}}$ Closely linked markers were also significantly associated with the trait.

e Two-factor ANOVA with AC10_0.3 as first component, $P<0.005$.

f Two-factor ANOVA with an interaction, $P<0.00005$. 
isolate and QTLs common to both isolates. Overall, more QTLs are necessary to confer partial resistance to PVY-Son41 (corresponding to the pathotype 1,2) than for complete resistance to PVY-To72 (corresponding to the pathotype 0). Thus, both nonspecific- and specific-effects QTLs are involved in this quantitatively inherited resistance against PVY. Other studies on fungus, bacteria, and nematode resistance brought the same observation. For example, QTLs involved in resistance to Phytophthora infestans in potato showed distinctly different effects against different $P$. infestans races (LeonardsSchippers et al. 1994). This study is the first report of QTLs for virus resistance with isolate-specific effect.

Similarly, QTLs with potyvirus-specific effect (against potyvirus $\mathrm{E}$ or against PVY) and genomic regions involved in the resistance to several distinct potyviruses have been detected. Four genomic regions (markers AC10_0.3 on chromosome Orange, CT204 on LG10, M11_1.5 on LG11, and TG124 on chromosome Noir) were effective against PVY and potyvirus E. A QTL for potyvirus E resistance was mapped in the vicinity of the pvr6 gene involved in pepper veinal mottle virus resistance (Caranta et al. 1996). Observations made for major potyvirus resistance genes, e.g., broad spectrum of action, were also true for quantitative trait loci. The frequent multipotyvirus effect of QTLs suggests a relationship between those potyviruses although general resistance factors were not detected, mainly genetic factors varying in their specificity level.

Broad-spectrum resistance can be explained either by the action of only one gene with pleiotropic effect or by linkage between distinct or related genes (gene family). Pleiotropic effects of resistance genes may result from (i) the recognition by the host gene of a common determinant (sequence) shared by the different potyviruses, (ii) the interruption of pathogenesis by the product of a single host gene (potyvirus may have conserved structures for pathogenesis), or (iii) the lack of a host component required for virus infection. Considering the recessive inheritance of line Perennial resistance and that factors from the susceptible parent contribute to the resistance, it is improbable that all the broad-spectrum QTLs detected were involved in the recognition of determinants shared by the potyviruses. But, we can expect that a single host factor is able to interrupt pathogenesis of several potyviruses. Some of the resistance factors could correspond to host genes involved in infection and/or defense mechanisms.

If broad spectrum resistance results from linkage between genes, these genes could be functionally related. As for fungal resistance genes showing a hypersensitive response (Pryor 1987), potyvirus resistance genes could share a common mode of action (resistance mechanism) but be triggered by strain/ potyvirus-specific sequences.

\section{Co-localization between QTLs and major genes.}

The genomic region around the RAPD marker AC10_0.3 (chromosome Orange) was shown to be involved in the resistance to both PVY isolates and potyvirus E and this marker explained a large part of the phenotypic variation observed for PVY-To72 and potyvirus E resistance. For the three resistances, the maximum LOD score values that indicated the most likely location of the QTL were observed between AC10_0.3 and R11_0.4, approximately 3 to $4 \mathrm{cM}$ from AC10_0.3, suggesting that the same QTL was involved in the different traits. Interestingly, the $p v r 2$ gene conferring a complete resistance to PVY(0), PVY(1), and TEV was bracketed by AC10_0.3 and R11_0.4 in another progeny, $3.5 \mathrm{cM}$ from AC10_0.3. This suggests that the line Perennial may carry a new allele at the $p v r 2$ locus, an allele with a quantitative effect on resistance and with a different spectrum of action: partially effective against PVY $(1,2)$ and potyvirus $E$ (the two known alleles at the $p v r 2$ locus were not) but ineffective against TEV (this line was highly susceptible to TEV). Moreover, the major-effect QTL is more effective against PVY-To72 than against PVY-Son41, which strengthens the possibility that this QTL is an allele of the $p v r 2$ locus. The genetic relationship between the QTL from the line Perennial and the $p v r 2$ locus is not clear enough at this time but the allelism hypothesis is under investigation. One way to test this hypothesis is to conduct in parallel a fine mapping of the locus (Paterson et al. 1990) and to characterize the resistance mechanism conferred by the major effect QTL in the vicinity of $p v r 2$ in order to compare with the resistance mechanism conferred by the two known resistance alleles at this locus (Arroyo et al. 1996).

Up to now, examples showing that qualitative and quantitative resistance may share a common genetic basis were reported on fungus-plant interactions (Freymark et al. 1993; Wang et al. 1994). In the present study, the same phenomenon was newly observed with virus resistance. Moreover, it can be extended to broad-spectrum genomic regions involved in distinct potyvirus resistance.

\section{MATERIALS AND METHODS}

\section{Mapping population.}

The potyvirus resistant parent, $C$. annuum line Perennial, was supplied by J. Singh (Punjab University, Luhiana, India). The susceptible one, C. annuum line Yolo Wonder, an inbred pepper line from California, contains the $L^{1}$ allele for resistance to tobacco mosaic virus. An $\mathrm{F}_{1}$-derived $\mathrm{DH}$ progeny of 94 lines was developed with in vitro androgenesis (Dumas de Vaulx et al. 1981). The interest of DH progeny for studying the genetics of multiple disease resistance has been previously reported (Lefebvre and Palloix 1996; Caranta et al. 1997). The $94 \mathrm{DH}$ lines were analyzed for molecular markers (RFLP and RAPD). Due to the absence of heterozygotes in DH progenies (and even though it precludes the estimation of dominance effects at the QTLs), dominant markers (RAPD) are as informative as co-dominant ones.

Mapping of the $p v r 2$ resistance gene was performed on the DH progeny (98 lines) obtained from the $F_{1}$ hybrid between two $C$. annuum lines: Vania (resistant line) from INRAMontfavet and H3 (susceptible line) from Ethiopia (described in Daubèze et al. 1995).

\section{Procedure for scoring virus resistance.}

The DH progeny obtained from the $\mathrm{F}_{1}$ hybrid between the lines Perennial and Yolo Wonder was evaluated for response to PVY isolates To72 (corresponding to the pathotype 0 according to the $p v r 2$ resistance system) and Son41 (corresponding to the pathotype 1,2) and potyvirus $\mathrm{E}$ with the AUSPC index combining both intensity of symptoms and incubation period: symptom intensity $(1=$ no symptom, $2=$ mild mosaic, and $3=$ severe mosaic and/or systemic necrosis) was evaluated every seventh day for 5 weeks after inoculation 
(Caranta and Palloix 1996). These PVY isolates were selected because they represented different levels of virulence. Resistant plants were also controlled with double antibody sandwich-enzyme-linked immunosorbent assays. Quantitative evaluation of the resistance was performed during three independent tests of 20 plants per DH line (Caranta and Palloix 1996). Narrow sense heritability estimates were calculated as described in Caranta and Palloix (1996).

\section{Molecular markers procedure and linkage map.}

Genomic DNA isolation, Southern blot and probes preparation, hybridization mapping, and RAPD assays were carried out as described by Lefebvre et al. (1995). Genomic DNA and cDNA probes from tomato (named TG for tomato genomic DNA, CD and CT for tomato cDNA) and pepper (named PG for pepper genomic DNA) were acquired from S. D. Tanksley and M. M. Kyle (Cornell University, Ithaca, NY). Decamer oligonucleotide primers for RAPD procedure were obtained from Operon Technologies (Alameda, CA).

The Mapmaker software (version 3.0b) (Lander et al. 1987) was used to construct the genetic linkage map with a minimum LOD score of 3.0 and a maximum recombination fraction of 0.3. Distances between markers were calculated with the Kosambi mapping function (Kosambi 1944). The "try," "ripple," and "compare" commands were used to include a locus in the preexisting linkage maps (Lefebvre et al. 1995; Caranta et al. 1997).

\section{QTL analysis.}

To identify genomic regions associated with PVY isolates and potyvirus $\mathrm{E}$ resistance, markers and resistance data were analyzed by ANOVA. Three ANOVA models (GLM procedure of Statistical Analysis System [SAS], 1989 SAS/STAT User's Guide, version 6, 4th ed., SAS Institute, Cary, NC) were performed on the average values over the three independent resistance tests (Edwards et al. 1987; Lefebvre and Palloix 1996): (i) The effect of each marker genotype (additive effect) was assessed by a single-factor ANOVA. A significance level of $P \leq 5.10^{-3}$ was employed. (ii) In order to decrease the error component, and consequently to detect regions with minor effects, we performed a two-factor ANOVA model with a first component corresponding to the markers linked to the major-effect genetic factors (AC10_0.3 in this study). The same significance level as for single-factor ANOVA was used. (iii) In addition to additive effect, digenic epistasis was tested with a two-factor ANOVA model with an interaction component between pairs of markers. In this case, a significance level of $P \leq 5.10^{-5}$ was employed. QTL effects were estimated as the percentage of phenotypic variation explained by the QTL, corresponding to the coefficient of determination from the ANOVA $\left(R^{2}\right)$. Complex ANOVA models were written to determine the global $R^{2}$ for each resistance, corresponding to the total part of variance explained by the set of the different QTLs revealed by the three consecutive ANOVA models. In these complex models, we included all the markers significantly associated with the trait (see Table 1 ), except for clusters of markers significantly associated with the trait and for which only the marker with the highest $R^{2}$ value was considered.

Because residuals from the ANOVA were not normally distributed (see Caranta and Palloix 1996), associations between markers and phenotypic variation for PVY and potyvirus E resistance were also determined with nonparametric tests (NPAR1WAY procedure of SAS, SAS Institute). The association of each marker genotype with the resistance value was performed with the Wilcoxon rank sum test and digenic epistasis with the Kruskal-Wallis test.

In order to more accurately estimate the chromosomal position of QTLs with important effect (QTL on chromosome Orange), the interval mapping method that localizes the effect of a QTL between pairs of linked genetic markers was employed (MapmakerQTL software; Lander and Botstein 1989).

\section{ACKNOWLEDGMENTS}

We thank F. Ponz for critical review of the manuscript, A. M. Daubèze, G. Nemouchi, T. Phaly, A. Blattes, and C. Ferriere for assistance, and the INRA Experimental Unit for support in plant experimentation.

\section{LITERATURE CITED}

Arroyo, R., Soto, M. J., Martínez-Zapater, J. M., and Ponz, F. 1996. Impaired cell-to-cell movement of potato virus $\mathrm{Y}$ in pepper plants carrying the $y^{\mathrm{a}}\left(p r 2^{1}\right)$ resistance gene. Mol. Plant-Microbe Interact. 9: 314-318.

Bauer, E., and Graner, A. 1995. Basic and applied aspects of the genetic analysis of the $y m 4$ virus resistance locus in barley. Agronomie 15: 469-473.

Blanco-Urgoiti, B., Sanchez, F., Dopazo, J., and Ponz, F. 1997. A straintype clustering of potato virus $\mathrm{Y}$ based on the genetic distance between isolates calculated by RFLP analysis of the amplified coat protein gene. Arch. Virol. 141:2425-2442.

Caranta, C., and Palloix, A. 1996. Both common and specific genetic factors are involved in polygenic resistance of pepper to several potyviruses. Theor. Appl. Genet. 92:15-20.

Caranta, C., Palloix, A., Gebre-Selassie, K., Lefebvre, V., Moury, B., and Daubèze, A. M. 1996. A complementation of two genes originating from susceptible Capsicum annuum lines confers a new and complete resistance to pepper veinal mottle virus. Phytopathology 86:739743.

Caranta, C., Palloix, A., Lefebvre, V., and Daubèze, A. M. 1997. QTLs for a component of partial resistance to cucumber mosaic virus in pepper: Restriction of virus installation in host-cells. Theor. Appl. Genet. 94:431-438.

Cook, A. A., and Anderson, C. W. 1959. Multiple virus disease resistance in a strain of Capsicum annuum. Phytopathology 49:198-201.

Daubèze, A. M., Hennart, J. W., and Palloix, A. 1995. Resistance to Leveillula taurica in pepper (Capsicum annuum) is oligogenically controlled and stable in Mediterranean regions. Plant Breeding 114: 327-332.

Dogimont, C., Palloix, A., Daubèze, A. M., Marchoux, E., GebreSelassie, K., and Pochard, E. 1996. Genetic analysis of broad spectrum resistance to potyviruses in haplodiploid progenies of pepper (Capsicum annuum L.). Euphytica 88:231-239.

Dumas de Vaulx, R., Chambonnet, D., and Pochard, E. 1981. Culture in vitro d'anthères de piment (Capsicum annuum L.): Amélioration des taux d'obtention de plantes chez différents génotypes par des traitements à $35^{\circ} \mathrm{C}$. Agronomie 1:859-864.

Edwards, M. D., Stuber, C. W., and Wendel, J. F. 1987. Molecularmarker-facilitated investigations of quantitative trait loci in maize. I. Numbers, genomic distribution and types of gene action. Genetics 116:113-125.

Fisher, M. L., and Kyle, M. M. 1994. Inheritance of resistance to potyviruses in Phaseolus vulgaris L. III. Cosegregation of phenotypically similar dominant responses to nine potyviruses. Theor. Appl. Genet. 89:818-823.

Fisher, M. L., and Kyle, M. M. 1996. Inheritance of resistance to potyviruses in Phaseolus vulgaris L. IV. Inheritance, linkage relations, and environmental effects on systemic resistance to four potyviruses. Theor. Appl. Genet. 92:204-212. 
Freymark, P. J., Lee, M., Woodman, W. L., and Martinson, C. A. 1993. Quantitative and qualitative trait loci affecting host-plant response to Exserohilum turcicum in maize (Zea mays L.). Theor. Appl. Genet. 87:537-544.

Gebre-Selassie, K., Marchoux, G., Delecolle, B., and Pochard, E. 1985. Variabilité naturelle des souches de virus Y de la pomme de terre dans les cultures de piment du sud-est de la France. Caractérisation et classification en pathotypes. Agronomie 5:621-630.

Gebre-Selassie, K., Marchoux, G., and Pochard, E. 1983. Biological and serological characterization of potato virus $Y$ strains affecting peppers and other related strains. Capsicum Newsl. 2:134-136.

Gilbert-Albertini, F., Lecoq, H., Pitrat, M., and Nicolet, J. L. 1993. Resistance of Cucurbita moschata to watermelon mosaic virus type 2 and its genetic relation to resistance to zucchini yellow mosaic virus. Euphytica 69:231-237.

Green, S. K., and Kim, J. S. 1991. Characteristics and control of viruses infecting peppers: A literature review. AVRDC Tech. Bull. No. 18.

Kosambi, D. D. 1944. The estimation of map distance from recombination values. Ann. Eug. 12:172-175.

Lander, E. S., and Botstein, D. 1989. Mapping mendelian factors underlying quantitative traits using RFLP linkage maps. Genetics 121: 185-199.

Lander, E. S., Green, P., Abrahamson, J., Barlow, A., Daly, M. J., Lincoln, S. E., and Newburg, L. 1987. Mapmaker: An interactive computer package for constructing primary genetic linkage maps of experimental and natural populations. Genomics 1:174-181.

Lefebvre, V., and Palloix, A. 1996. Both epistatic and additive effects of QTLs are involved in polygenic induced resistance to disease: A case study, the interaction pepper - Phytophthora capsici Leonian. Theor. Appl. Genet. 93:503-511.

Lefebvre, V., Palloix, A., Caranta, C., and Pochard, E. 1995. Construction of an intraspecific integrated linkage map of pepper using molecular markers and doubled haploid progenies. Genome 38:112-121.

Légnani, R., Gognalons, P., Gébré Sélassié, K., Marchoux, G., Moretti, A., and Laterrot, H. 1996. Identification and characterization of resistance to tobacco etch virus in Lycopersicon species. Plant Dis. 80: 306-309.
Leonards-Schippers, C., Gieffers, W., Schaüfer-Pregl, R., Ritter, E., Knapp, S. J., Salamini, F., and Gebhardt, C. 1994. Quantitative resistance to Phytophthora infestans in potato: A case study of QTL mapping in a allogamous plant species. Genetics 137:67-77.

McMullen, M. D., and Louie, R. 1991. Identification of a gene for resistance to wheat streak mosaic virus in maize. Phytopathology 81: 624-627.

Palloix, A. 1992. Diseases of pepper and perspectives for genetic control. Pages 120-126 in: Genetics and Breeding on Capsicum and eggplant. Proc. EUCARPIA Meeting, 8th. P. Bellti and L. Quagliotti, eds.

Palloix, A., and Kyle, M. M. 1995. Proposed revision of gene nomenclature for potyvirus resistance genes in Capsicum sp. Capsicum Eggplant Newsl. 14:26-29.

Paterson, A. H., Deverna, J. W., Lanini, B., and Tanksley, S. D. 1990 Fine mapping of quantitative trait loci using selected overlapping recombinant chromosomes in a interspecific cross of tomato. Genetics $124: 735-742$

Pochard, E. 1977. Localization of genes in Capsicum annиum L. by trisomic analysis. Ann. Amélior. Plant. 27:255-266.

Provvidenti, R., and Hampton, R. O. 1992. Sources of resistance to viruses in the Potyviridae. Arch. Virol. 5:189-211.

Provvidenti, R., and Hampton, R. O. 1993. Inheritance of resistance to white lupin mosaic virus in common pea. HortScience 28:836-837.

Pryor, T. 1987. The origin and structure of fungal disease resistance genes in plants. Trends Genet. 3:157-161.

Wai, T., and Grumet, R. 1995. Inheritance of resistance to watermelon mosaic virus in the cucumber line TMG-1: Tissue-specific expression and relationship to zucchini yellow mosaic virus resistance. Theor Appl. Genet. 91:699-706.

Wang, G. L., Mackill, D. J., Bonman, J. M., McCouch, S. R., Champoux, M. C., and Nelson, R. J. 1994. RFLP mapping of genes conferring complete and partial resistance to blast in a durably resistant rice cultivar. Genetics 136:1421-1434.

Ward, C. W., and Shukla, D. D. 1991. Taxonomy of potyviruses: Current problems and some solutions. Intervirology 32:269-296.

Young, N. D. 1996. QTL mapping and quantitative disease resistance in plants. Annu. Rev. Phytopathol. 34:479-501. 